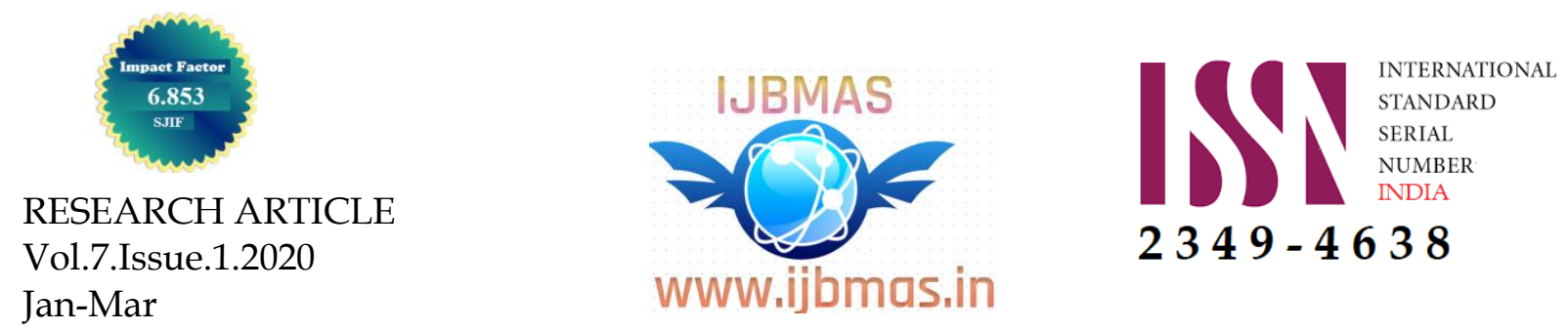

INTERNATIONAL JOURNAL OF BUSINESS, MANAGEMENT AND ALLIED SCIENCES (IJBMAS)

A Peer Reviewed and refereed Journal

\title{
IMPACT OF CURRENT ACCOUNT IMBALANCE ON UNEMPLOYMENT
}

\author{
APURVA TUDEKAR \\ Student, Mumbai School of Economics and Public Policy \\ Email: apurva.tudekar@gmail.com \\ DOI: 10.33329/ijbmas.7.1.47
}

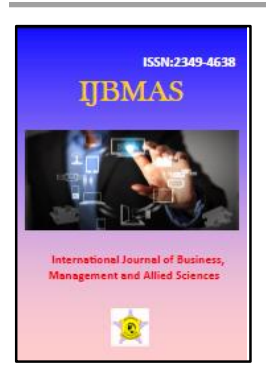

\begin{abstract}
This paper tries to explore the effects of current account deficit on the prevalent unemployment that affects the development of the Indian economy. A widening in the current account imbalance and rising unemployment in recent times makes the analysis of these factors significant. Thus using the analytical framework of a bivariate Granger Causality test in a Vector Autoregressive(VAR) model, from the year 1991 to 2018, it attempts to find out if there is a significant two way relationship between the variables Current account balance(in current \$US) and Unemployment (measured as a percentage of total labour force) .It also performs the Johansen's Test for Cointegration in a Vector Error Correction Model(VECM) to test for long run relationship between the said variables. Further, this paper also suggests policy measures necessary for ameliorating the conditions of the impoverished and for holistic growth of the country.

Keywords: Development, Current Account, Unemployment, Granger Causality, Vector Autoregressive, Johansen's Test, Vector Error Correction Model
\end{abstract}

\section{Introduction:}

Current account deficit has two implications, it can either lead to improvement in the competitiveness of the exports in the long run which is considered as a positive signal for growth or it is bad for the economy if the deficit is caused due to the financial mismanagement leading to reduction in the savings (Blanchard and Milesi-Ferretti , 2011).Macroeconomic imbalances over a sustained period of time definitely affects the poor because it leads to inflation, decline in output and growth(Brian Ames, Ward Brown, Shanta Devarajan, Alejandro Izquierdo, 2001).

India has been facing problems in the current account since the 1980's. Its deficit during the 1991 Balance of Payment crisis was as high as $4 \%$ out of the total Gross Domestic Product. The deficit has narrowed down to $0.7 \%$ of the GDP in 2018-19 from 1.8\% in the year 2017-18.Similarly, poverty headcount ratio during 1980 was at a peak at $54.8 \%$ out of total population .It has declined to $45.9 \%$ in 1993 and further to $21.2 \%$ in 2010.As per the latest report by United Nations Development Plan Report(UNDP) which was released in 2018, revealed that India is no longer has the largest poor 
population. In fact poverty has reduced by almost half from $54.7 \%$ to $27.5 \%$ in the last ten years. However, unemployment is rising steadily and as per the Ministry of Labour, all India average unemployment stands at $6.2 \%$, which is the highest in 45 years. This leads to the question of the impact, current account deficit has in particular on the unemployment scenario of the country. The primary reason for selecting unemployment rate as the indicator is that it reflects jobless growth, underdeveloped manufacturing sector and a struggling agriculture sector, magnitude of poverty to a great extent.

This paper is organised as follows: the overall trends in current account, poverty and unemployment. Section II employs the Granger Causality test in a VAR model to test the impact of current account on the unemployment rate and Johansen's test for cointegration in a VECM for testing the long run relationship between the same. Section III analyses of the results. Section IV makes concluding remarks and suggestions.

Trends in current account, poverty and unemployment

Current Account Deficit

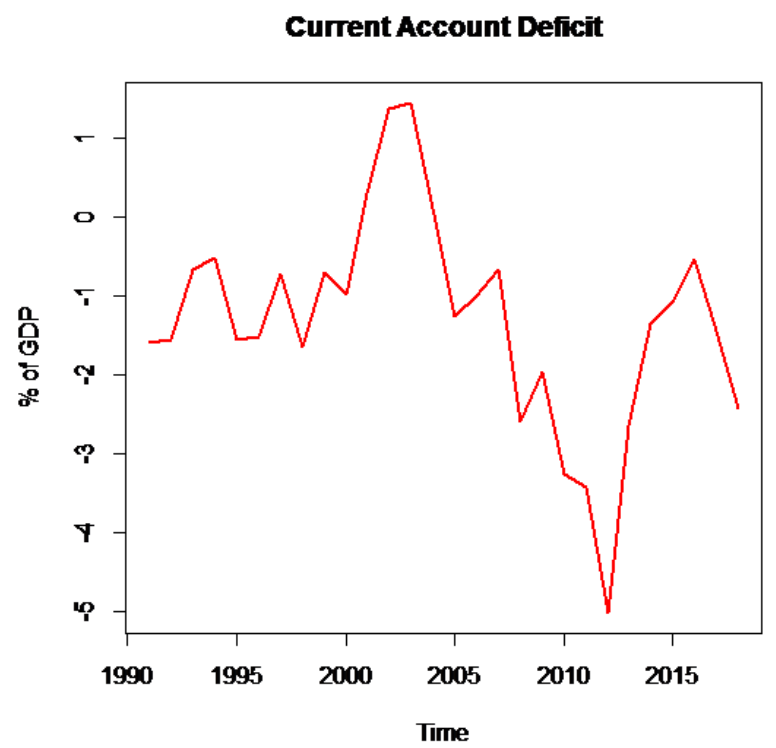

Figure 1.1

\section{Source: World Bank}

The above figure shows the share of current account deficit as a percentage of GDP from the period 1991 to 2018. The year 1991 to 1994 shows signs of current account consolidation after the Balance of Payment Crisis. There has also been a rise in capital investments, foreign direct investments. A series of liberalization reforms in the economy helped in reducing the imbalance. The year from 2001-2004 shows a positive deficit, indicating that there was an increase in exports and invisibles like services (IT, software).One of the sharpest fall in the CAD happened in 2012, mainly due to the Global Financial Crisis. The deficit has been narrowing down till it came to a halt in 2016 and has been worsening since then. The main causes of this deterioration are the dramatic slowdown in exports, surge in imports, reduction in foreign investment (direct and portfolio). As a result our commercial borrowings, external assistance show an upward trend. 


\section{Unemployment}
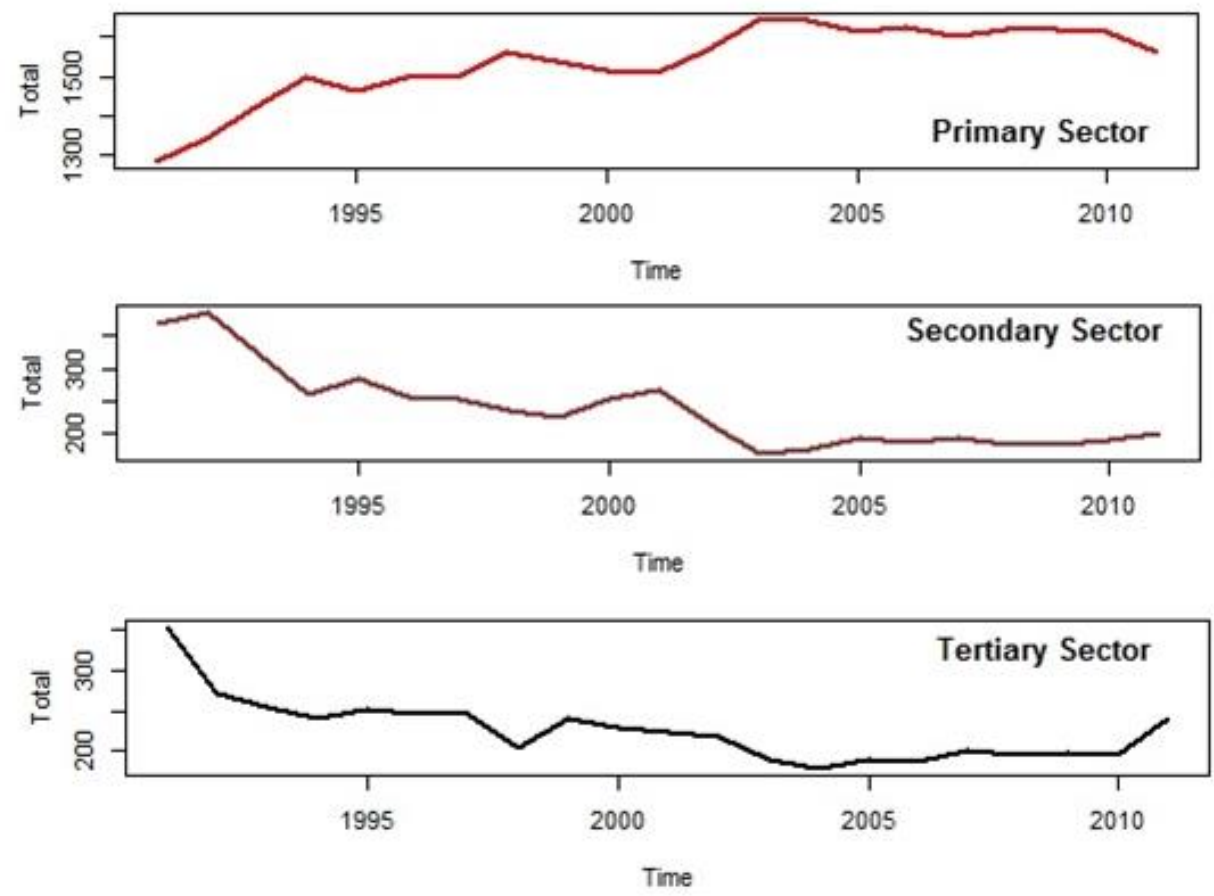

Figure 1.2: Unemployment in the Rural Economy from 1991-2018

Source:NSSO (various rounds)

Figure 1.3: Unemployment in the Urban Economy from 1991-2018
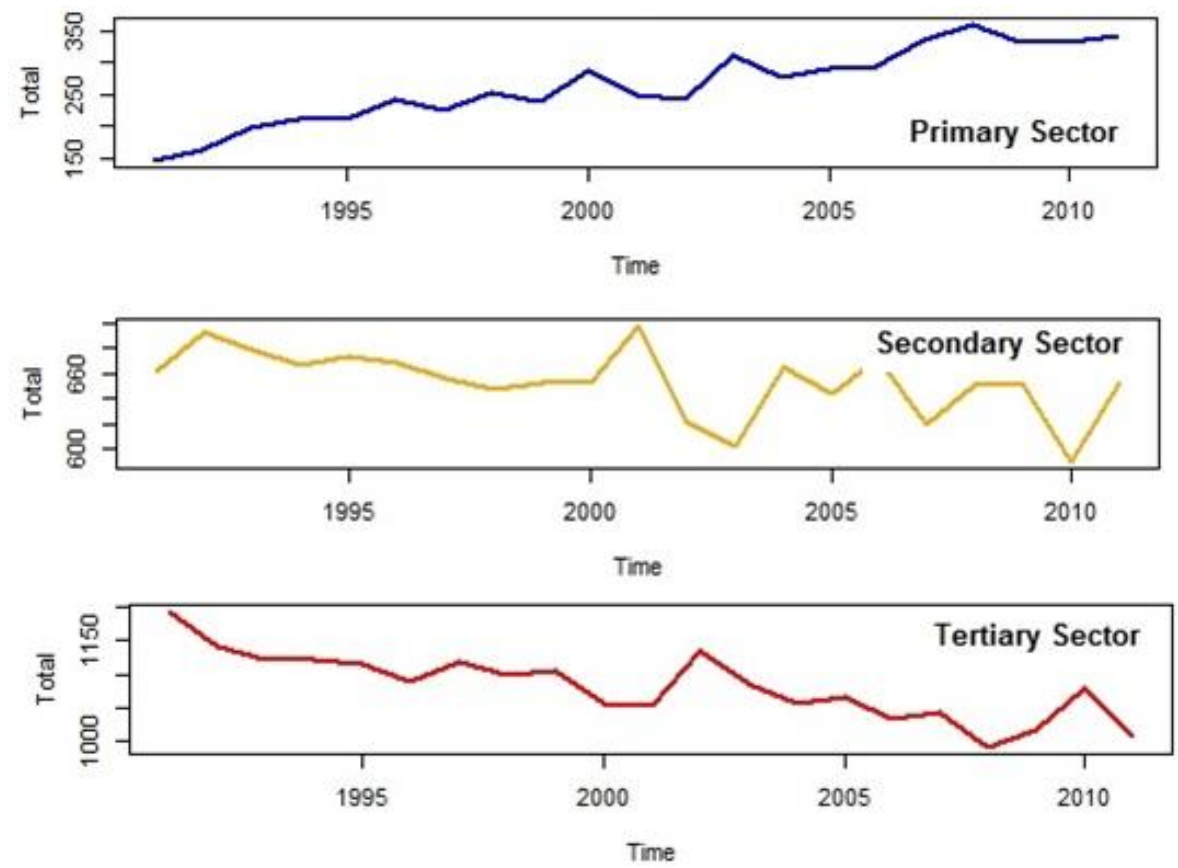

Source:NSSO (various rounds)

Figure 1.2 and 1.3 depict the trends in unemployment in rural and urban economy from 1991 to 2018.The actual data is collected from the National Sample Survey Organisation which conducts various rounds to gather data on a disaggregated level: primary, secondary and tertiary as well as male and female. It is expressed in per thousand terms. In the rural economy the unemployment was rising before 1995 mainly due rising poverty. The unemployment is rising in the primary sector, consistently, it's only in 2017-18 that the primary sector shows a dip in the unemployment, which 
indicates fall in labour force of the agricultural sector.However, it cannot be discounted that the exit from primary sector requires adequate job opportunities in the secondary sector which is in a dismal state in the rural economy. Both the secondary and tertiary sector show a spike from 2010 onwards. This highlights a major fact that manufacturing sector contribution that is the valued added has reduced from $17 \%$ in the early 2000 's to just $14 \%$ since 2015 .The statistics validates this point.In Figure 1.3 , for the urban economy, once again secondary sector(electricity, mining, manufacturing) show the highest level of unemployment. Though, the tertiary sector shows a lower level of unemployment the problem runs deeper. Immediately after liberalisation, unemployment in the tertiary sector was quite high.It is only after the reforms that more and more people got absorbed in the services sector. It is reflective of the high degree of urbanisation happening at $34 \%$.The increasing unemployment in the primary sector proves that urbanisation is indeed happening at a swift rate all over India.

\section{Poverty}

Table 2.1:National Poverty Estimates(\% below the poverty line)

\begin{tabular}{|c|c|c|c|}
\hline Year & Rural (\%) & Urban(\%) & Total(\%) \\
\hline $1993-94$ & 50.1 & 31.8 & 45.3 \\
\hline $2004-05$ & 41.8 & 25.7 & 37.2 \\
\hline $2009-10$ & 33.8 & 20.9 & 29.8 \\
\hline $2011-12$ & 25.7 & 13.7 & 21.9 \\
\hline
\end{tabular}

Source:Poverty Estimates, 2011 - 12, Planning Commission; Report of the Expert Group to

Review the Methodology for Estimation of Poverty (2009) Planning Commission; PRS.

The given table demonstrates the poverty estimates from 1993 till 2012.It is seen that both rural and urban poverty have reduced substantially and almost halved from $50 \%$ to almost $25 \%$ in the case of rural areas.In the urban areas, the dip is significant from almost $32 \%$ to $22 \%$.There isn't any official data on recent national poverty estimates.However, it is feared that the poverty may have shot up in the rural areas mainly due to its endogeneity with rising unemployment.The MGNREGA data on average days of employment shows a dip from 46 to 45 days from 2016-17 and 2017 -18.Similarly, the increment in wages per day is less than 1\% from 2016 to 2018. All these indicators could be a signal of an increasing poverty in general.

\section{Methodology and Results:}

The data is collected from the World Bank database with the International Monetary Fund, Balance of Payments Statistics Yearbook and data files, as the source for Current Account balance(BOP, current \$US) variable.The current account is taken as the sum of net exports and imports, net primary and secondary income. Unemployment (total percentage of total labour force) variable is modelled as per the International Labour Organisation(ILO) estimates from the World Bank with ILO, ILOSTAT as the source organisation.

The Granger Causality test, Granger(1969) is applied to test the macroeconomic effect of current account balance on the unemployment from the year 1991-2018 in a VAR framework. 
Equations: $\quad \mathrm{UNEt}=a+\sum_{i=1}^{n} b U N E t-1+\sum_{i=1}^{n} d C A t-1+e 1 \ldots(1)$

$C A t=a+\sum_{i=1}^{n} g C A t-1+\sum_{i=1}^{n} h U N E t-1+e 2$

The above equations tests for Granger Causality based on the research question whether current account imbalances (CA) causes unemployment(UNE) but we also test for the reverse. The variables $e 1$ and $e 2$ indicate innovations.The number of lags chosen is five as per the Akaike Information Criterion(AIC) for model adequacy.

The Null Hypothesis states that current account imbalance does not granger cause unemployment as well as unemployment does not granger cause current account imbalances, in the short run.

Ho: $b=d=0 \ldots .(3)$

Ho: $g=h=0 \ldots .(4)$
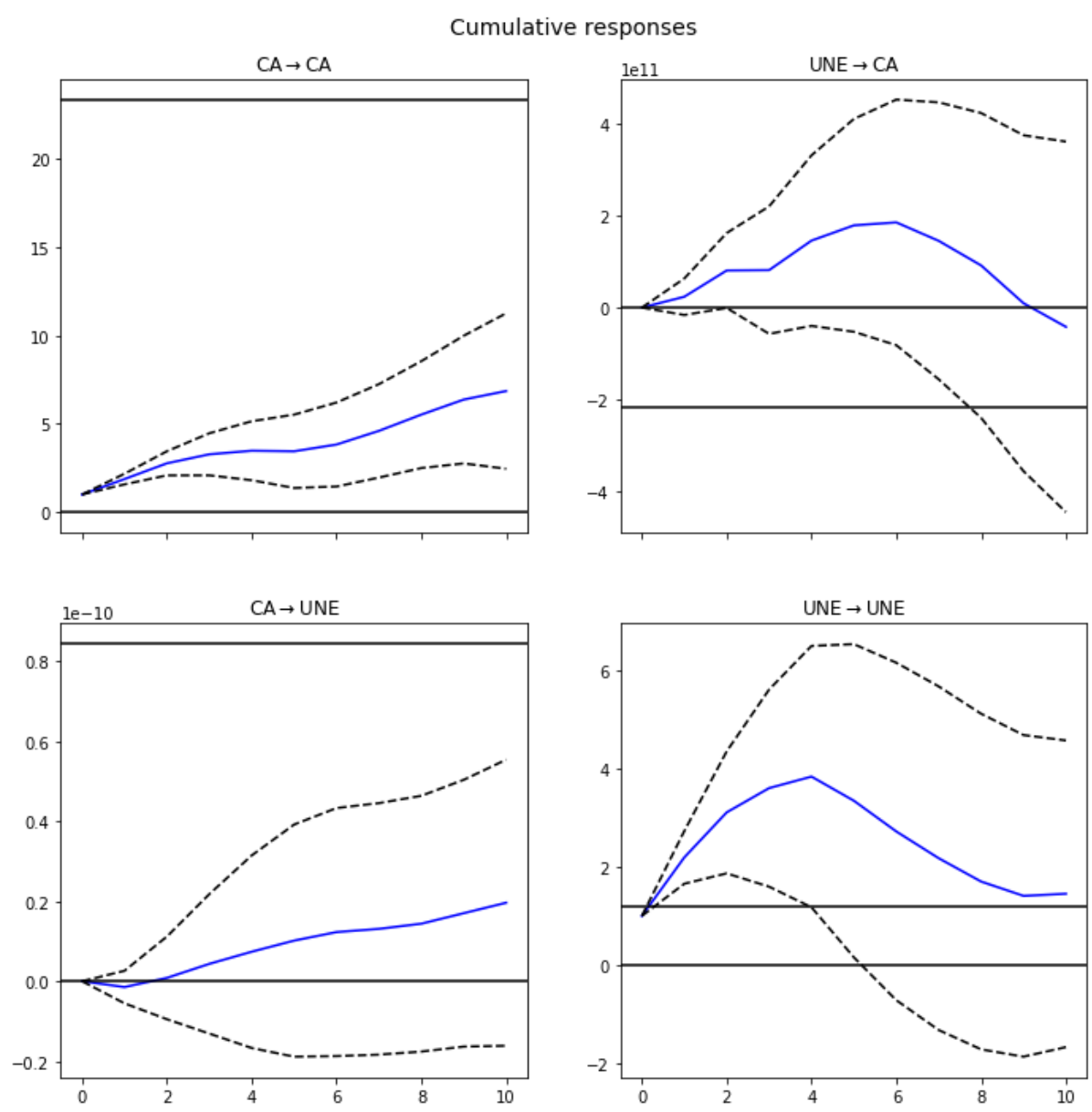

Figure 1.3

H_0: CA does not Granger-cause UNE: fail to reject at 5\% significance level. Test statistic: 1.034, critical value: $2.621>$, p-value: $0.420>$ 

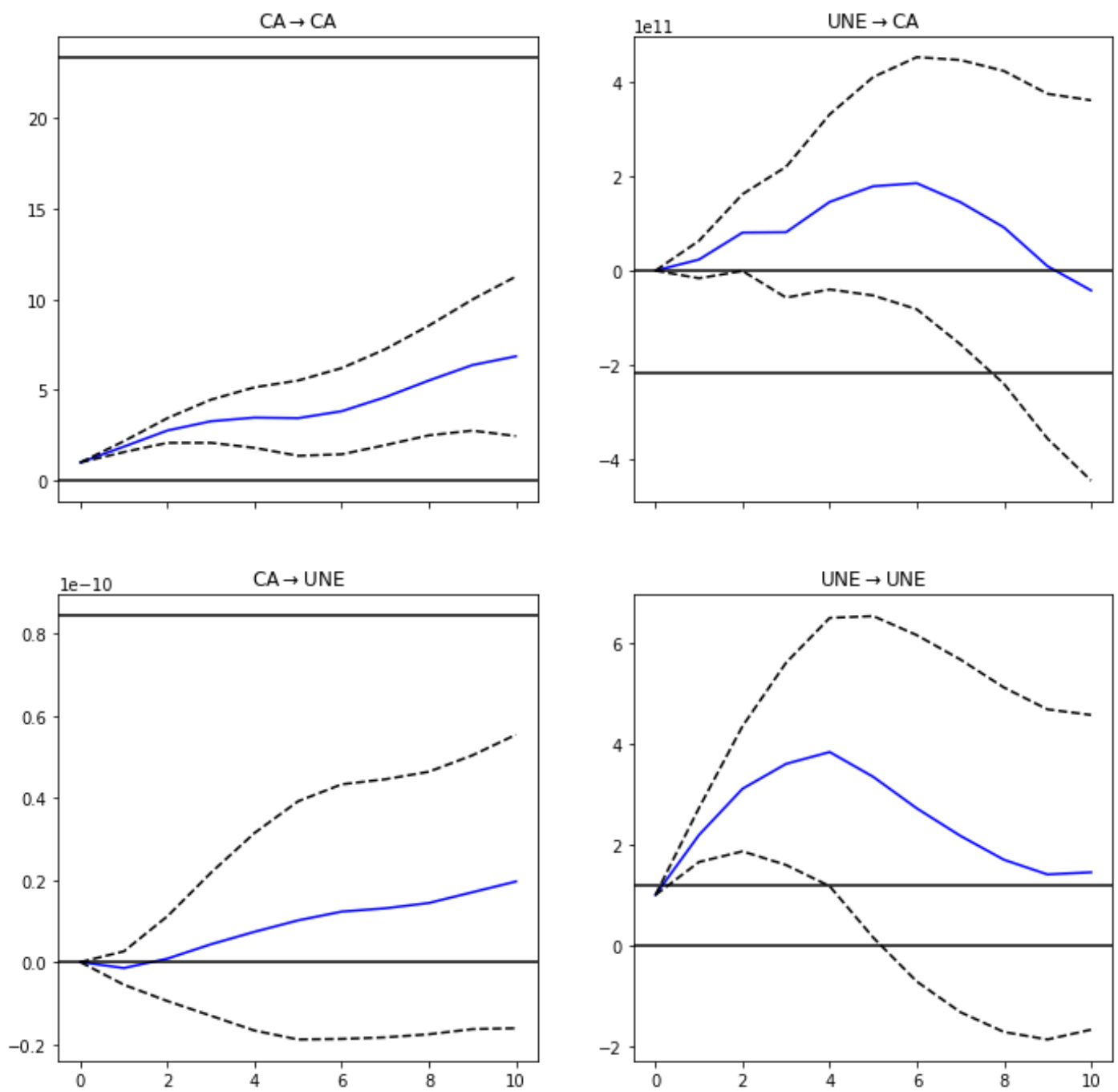

Figure 1.4

H_0: UNE does not Granger-cause CA: reject at 5\% significance level. Test statistic: 8.709, critical value: $2.621>$, p-value: $0.000>$

Correlation Matrix Table 2.2

Correlation matrix of residuals

\begin{tabular}{|l|l|l|}
\hline & CA & UNE \\
\hline CA & 1.000000 & -0.014645 \\
\hline UNE & -0.014645 & 1.000000 \\
\hline
\end{tabular}

Johansen's Cointegration test in a VECM framework.

The Johansen's test for cointegration tests the long run relationship between the variables(1991).The test is conducted to see if there is a common trend between the variables, current account balance and unemployment.The Vector Error Correction model is used with the assumption that there is a long run cointegration relationship between the variables.The trace statistic and the 
maximum eigenvalue statistic also known as max statistics are the rank test used to test the hypothesis for cointegration.It tells the number of cointegration relations that exist in the equation.

The trace statistics tests for the number of characteristic roots:

It is given by:

$\lambda \operatorname{trace}(\mathrm{r})=-\mathrm{T} \sum_{i=r+1}^{n} \ln (1-\hat{\lambda} i)$

$\lambda \max (\mathrm{r})=-\mathrm{T} \ln (1-\hat{\lambda} r+1)$

Table 2.3

Trace Statistics:

\begin{tabular}{|l|l|l|l|l|}
\hline Null Hypothesis & Statistic & $90 \%$ & $95 \%$ & $99 \%$ \\
\hline$r<=0$ & 19.050 & 15.0006 & 17.1481 & 21.7465 \\
\hline$r<=1$ & 5.276 & 2.7055 & 3.8415 & 6.6349 \\
\hline
\end{tabular}

Table 2.4:

Max Statistics:

\begin{tabular}{|l|l|l|l|l|}
\hline Null Hypothesis & Statistic & $90 \%$ & $95 \%$ & $99 \%$ \\
\hline $\mathrm{r}<=0$ & 13.774 & 15.0006 & 17.1481 & 21.7465 \\
\hline $\mathrm{r}<=1$ & 5.276 & 2.7055 & 3.8415 & 6.6349 \\
\hline
\end{tabular}

\section{Section III: Analyses of the results}

The above results have been tested for short run relationship as well as long run relationship using Granger causality test and Johansen's test for cointegration respectively.Figure 1.3 tests for the null hypothesis that current account imbalance does not cause unemployment in the short run.At $5 \%$ level of significance the null is not rejected and hence it could be inferred that current account imbalances do not cause unemployment in India at least for a brief period.The blue line in the figure displays the significance level.At the same time, it is tested whether unemployment causes current account imbalances.It fails to reject the null in a vector autoregressive framework, using Granger causality test.The plots show the impulse response functions. The lag length is decided according to the AIC (Akaike Information Criterion).

Table 2.2 shows the correlation matrix obtained signifying the extent of correlation between current account and unemployment.The matrix shows a negative correlation between the variables, it proves the fact that when unemployment is rising in the economy the current account is running in a deficit and vice versa.Looking at the literature on long term relation between current account, unemployment, inflation(RBA, 1994) is also incorporated in the study by testing for the long run relationship between current account and unemployment.Vector error correction model is used with the assumption of a long run relationship.Johansen's test for cointegration is used for analysing the undifferenced data.As per the methodology, we estimate the characteristic roots of the matrix using $\lambda$ trace and $\lambda \max$ statistics.Table 2.3 shows the trace statistics value.The null hypothesis of no 
cointegration fails to be accepted as the statistic 19.05 is greater than 17.1481 and hence the alternate hypothesis for 1 or more than 0 cointegrating factor holds true at $5 \%$ level of significance. Similarly, maximum eigenvalues give a more sharper difference $(0,1)$ however the max statistics fails to give a conclusive result as 13.77 is less than the tabulated values, hence we fail to reject the null of no hypothesis. When the cointegrating relationship is checked at $r=1$ against the alternative $r=2$, for the max statistics the null hypothesis of no cointegration is rejected at $5 \%$ level of significance since the statistic is greater than the critical value. The trace statistics doesn't give the exact number of cointegrating relationship at $r<=1$ against the alternative $r>1$, though the test concluded at more than one cointegrating relationship. Hence, it can be assumed that there are two cointegrating factors leading to the statement that there is a long run relationship between current account imbalances and unemployment in the Indian Economy.

The absence of a short run causal relation between current account and unemployment points to the fact that current account imbalances do not have much of an impact on the unemployment situation. There are various other factors affecting unemployment in the short term like inflation, sectoral slowdown in agriculture, manufacturing, poverty .However sustained increase in current account deficits and unemployment have a long run relationship . A prolonged deficit in the current account signifies deteriorating export competitiveness, reduction in foreign inflows impacting economic growth. At the same time, there are many factors responsible for unemployment like surge in female unemployment, rise in rural unemployment, rising job aspirations, fall in investment rate affecting job creation and a struggling secondary sector.

\section{Conclusion and Suggestions}

The above study indicates the long term socioeconomic impact due to current account imbalances in the Indian economy. With a four decade high unemployment rate pegged at $7.7 \%$ as per CMIE(Centre for Monitoring Indian Economy) and a worsening current account imbalance, it becomes important to study it's protracted influence on the growth of the economy. The presence of a cointegrating relationship reveals the need to tackle the problem as it has a distributional consequence. One of the solution lies in improving the vocational training. Operation Twist started by the RBI is unlikely to boost investment if it is not followed by measures to attract domestic capital investment, foreign investment and clear the backlog of public sector infrastructure projects. Exports have to be reinvigorated by streamlining the export credit availability, augmenting the share of labour force in manufacturing .Poverty continues to be a burning issue as rural poverty has spiked and hence alleviating it requires mitigation of unemployment to create a better future for the youth of India and in turn fix the growth slowdown.

\section{References:}

[1]. Devulapalli, S. (2019, December 3). India's rural poverty has shot up. Retrieved February 9, 2020, from https://www.livemint.com/news/india/rural-poverty-has-shot-up-nso-datashows-11575352445478.html

[2]. Contributors, E. (2020, January 24). View: What this Budget can offer to fix India's unemployment problem. Retrieved February 7, 2020, from https://economictimes.indiatimes.com/news/economy/policy/view-what-the-budget-canoffer-to-fix-indias-unemployment-problem/articleshow/73574707.cms

[3]. India . (n.d.). Retrieved January 20, 2020, from https://data.worldbank.org/country/india

[4]. Download Reports: Ministry of Statistics and Program Implementation: Government Of India. (n.d.). Retrieved January 25, 2020, from http://mospi.gov.in/recent-reports

[5]. Milesi-Ferretti, G.-M., \& Blanchard, O. (2011). (Why) Should Current Account Balances Be Reduced? Staff Discussion Notes, 11(03), 1. doi: 10.5089/9781462384860.006

[6]. Izquierdo, A., Brown, W., Ames, B., \& Devarajan, S. (2001). Macroeconomic Policy and Poverty Reduction. Pamphlet Series. doi: 10.5089/9781589060173.054 
[7]. Database on Indian Economy. (n.d.). Retrieved January 20, 2020, from https://dbie.rbi.org.in/DBIE/dbie.rbi?site=publications

[8]. Human Development Reports. (n.d.). Retrieved from http://hdr.undp.org/en/2018-update

[9]. Johansen, S. (1991). Estimation and Hypothesis Testing of Cointegration Vectors in Gaussian Vector Autoregressive Models. Econometrica, 59(6), 1551. doi: 10.2307/2938278

[10]. Himanshu. (2019, March 14). Opinion: What happened to poverty estimation in the country. Retrieved January 25, 2020, from https://www.livemint.com/opinion/columns/opinionwhat-happened-to-poverty-estimation-in-the-country-1552584031417.html

[11]. Ballantyne, A., Voss, D. D., \& Jacobs, D. (n.d.). Unemployment and Spare Capacity in the Labour Market. Retrieved from https://rba.gov.au/publications/bulletin/2014/sep/pdf/bu0914-2.pdf

[12]. Kumar, S., Ellison, C., \& Boodoosingh, A. (2014, November 4). Three ways to boost growth in India. Retrieved January 24, 2020, from

https://www.livemint.com/Opinion/nYrWgfKfIORfdBNh1XBC1O/Three-ways-to-boostgrowth-in-India.html

[13]. Granger, C. W. J. (1969). Investigating Causal Relations by Econometric Models and Crossspectral Methods. Econometrica, 37(3), 424. doi: 10.2307/1912791

[14]. Lütkepohl, H. (2004). Vector Autoregressive and Vector Error Correction Models. Applied Time Series Econometrics, 86-158. doi: 10.1017/cbo9780511606885.004 